\title{
IMPLEMENTASI NILAI-NILAI SIBALIPARRI (STUDI KASUS PENDIDIKAN AGAMA DI MANDAR)
}

\author{
Idham*); Ulfiani Rahman \\ Balai Litbang Agama Kementerian Agama Makasar, Sulawesi Selatan \\ *)email: idbodi@yahoo.com
}

Paper Accepted: 25 Maret 2020 Paper Reviewed: 26-31 Maret 2020 Paper Edited: 01-15 April 2020 Paper Approved: 25 April 2020

\begin{abstract}
ABSTRAK
Olehnya itu, penelitian ini akan memaparkan tentang nilai-nilai sibaliparri dan kaitannya dengan pendidikan keagamaan dalam lingkup rumah tangga. Poin terpentingnya adalah pemaparan tentang nilai-nilai sibaliparri dan dengan aspek pendidikan keagamaan. Keteladanan yang menjadi bagian dari konsepsi sibaliparri, selain sarat dengan nilai-nilai agama, juga bisa menjadi modal sosial dalam upaya pembentukan karakter manusia Mandar yang religius dan berbudaya, sebagaimana yang menjadi cita-cita luhur perjuangan pembentukan Provinsi Sulawesi Barat, yaitu terwujudnya provinsi malaqbi (bermartabat). Penelitian ini menggunakan metodologi kualitatif yang dimaksukan untuk menggambarkan implementasi nilai-nilai sibaliparri dengan studi kasus pendidikan keagamaan di Mandar menggunakan studi literatur. Teknik pengumpulan data penelitian ini menggunakan studi literatur atau dokumen, baik dari jurnal, makalah, buku maupun sumber informasi lainnya yang membahas mengenai implementasi nilai-nilai sibaliparri. Literatur atau dokumen adalah peristiwa yang sudah berlalu. Dokumen atau literatur bisa berbentuk tulisan, gambar atau karya-karya monumental dari seseorang (Sugiyono, 2012). Sibaliparri adalah nilai-nilai kebudayaan yang sudah lama mengakar dalam tatanan kehidupan sosial masyarakat Mandar. Sibaliparri berasal dari suku kata si yang artinya saling, bali yang berarti lawan, namun jika diawali dengan me menjadi mebali bermakna menjawab atau membantu, sementara parri berarti susah. Sibaliparri berarti saling membantu dalam segala sesuatu baik secara materi maupun spiritual.
\end{abstract}

Kata Kunci: Sibaliparri, Pendidikan Agama, Mandar

\section{PENDAHULUAN}

Secara umum, Mandar selain dikenal sebagai bahasa suku, juga penamaan yang kerap digunakan untuk menunjuk pada sebuah komunitas yang mendiami wilayah Sulawesi Barat (Sulbar). Pemaknaan Mandar dalam konteks geografis ini, tentu saja berbeda pemaknaannya dalam konteks bahasa sebagai identitas.

Mandar dalam konteks geografis adalah gugusan wilayah eks persekutuan kerajaankerajaan kerajaan Pitu Baqbana Binanga (PBB) - tujuh kerajaan di muara dan Pitu Ulunna Salu (PUS) - tujuh kerajaan hulu.

Sementara pemaknaan Mandar dalam konteks bahasa suku, hingga saat ini masih menjadi perdebatan. Pasalnya ada beberapa sub suku, seperti Pannei, Pattae, Pakkaoq, Pallea, Mamasa, Mamuju, Baras dan lainnya merasa diri bukan bagian dari orang Mandar. Alasannya sederhana, karena perbedaan bahasa (Bodi, 2010:1).

Meski demikian, nilai kebudayaan dan mitologi sejarah manusia pertama di Mandar menjadi titik temu. Mereka mengakui berasal dari nenek moyang yang sama, yaitu; Pongkapadang dan Torije'ne yang turunan kemudian menyebar dan berdiam wilayah Pitu Ba'bana Binanga, Pitu Ulunna Salu dan Karua Tiparitina Uhai yang kesemuanya masuk dalam wilayah Sulawesi Barat (Bodi, 2019:11-54). 
Sementara dari segi nilai kebudayaan, warga yang mendiami wilayah Sulawesi Barat ini dikenal sebagai masyarakat terbuka. Hal itu tidak hanya terlihat pada corak kehidupan sosial mereka yang multikultur, tapi juga pada cara pandang hidup mereka. Mua' didundumi uai randanna to Mandar, to Mandarmi tu'u tau, andiammi tau mala sikira-kira adae' (Jika air beningnya orang Mandar sudah diminum, maka kita sudah termasuk orang Mandar, dan itu berarti kita tidak bisa lagi untuk saling berburuk sangka, apalagi sampai mencari keburukan) (Bodi, 2008:22).

Filosofi hidup ini menggambarkan kebesaran hati orang-orang Mandar untuk menerima orang luar sebagai bagian dari dirinya, sebab mereka yang telah meminum air putihnya orang Mandar, tidak hanya bersedia menjadi bagian dari orang Mandar, tapi juga bersedia mengikuti segala aturan dan tata perilaku yang berlaku di tanah Mandar. Olehnya itu, Mandar tidak didasarkan pada suku dan bahasa, melainkan pada pengamalan nilai-nilai kebudayaan yang hidup dan berkembang di tanah Mandar.

Pandangan ini didasarkan pada ungkapan Saiful Singrang, salah seorang budayawan Mandar, ia mengatakan, bahwasanya yang membentuk sebuah suku adalah kebudayaan. Olehnya itu, ia pun mencontohkan, jika ada orang Jawa datang ke Mandar kemudian mengamalkan budaya Mandar secara utuh, maka secara otomatis ia telah menjadi orang Mandar (Singrang: 1981: XVII).

Cara pandang seperti ini, tidak hanya terlihat dalam pola relasi sosial mereka, tapi juga dalam ruang lingkup rumah tangga, ruang kehidupan yang sifatnya privat dan prinsipil. Umumnya orang Mandar tidak mempersoalkan latar-latar belakang etnik seseorang dalam membangun mahligai rumah tangga, karena yang terpenting adalah bagaimana membangun relasi kerja sama yang baik, sebagaimana ungkapan yang mengatakan, "muaq meloqo maqita tobaine, itai tabaine iya mala disiolang sibaliparri" (jika hendak beristri, maka carilah perempuan yang bisa diajak bekerjasama atau saling membantu) (Bodi, 2010:90).

Olehnya itu, keterlibatan perempuan dalam pencarian nafkah, oleh budaya tertentu mungkin akan dipandang sebagai sesuatu tabu, kurang elok dan tidak pantas, namun dalam konteks budaya Mandar, hal itu dinilai sebagai sesuatu yang biasa, bahkan dianggap terhormat.

Dikatakan demikian, karena praktik hidup seperti adalah bagian dari implementasi nilainilai luhur sibaliparri, sebuah filosofi hidup yang menekankan pentingnya kerjasama antara suami-isteri demi kelanggengan harmonisasi kehidupan rumah tangga. Bahkan, hingga saat ini, praktik sibaliparri ini masih mengakar kuat dalam tradisi kebudayaan masyakat Mandar, khususnya di wilayah pesisir. Orang Mandar memberlakukan sibaliparri karena menganggap keluarga adalah milik bersama, sehingga segala sesuatu yang berkaitan dengannya menjadi tanggungjawab suami-istri (Ismail, 2012:44).

Olehnya itu, penelitian ini akan memaparkan tentang nilai-nilai sibaliparri dan kaitannya dengan pendidikan keagamaan dalam lingkup rumah tangga. Poin terpentingnya adalah pemaparan tentang nilai-nilai sibaliparri dan dengan aspek pendidikan keagamaan. Keteladanan yang menjadi bagian dari konsepsi sibaliparri, selain sarat dengan nilai-nilai agama, juga bisa menjadi modal sosial dalam upaya pembentukan karakter manusia Mandar yang religius dan berbudaya, sebagaimana yang menjadi cita-cita luhur perjuangan pembentukan Provinsi Sulawesi Barat, yaitu terwujudnya provinsi malaqbi (bermartabat).

\section{METODE PENELITIAN}

Penelitian ini menggunakan metodologi kualitatif yang dimaksukan untuk menggambarkan implementasi nilai-nilai sibaliparri dengan studi kasus pendidikan keagamaan di Mandar menggunakan studi literatur.

Studi kasus merupakan sebuah eksplorasi dari suatu sistem yang terikat atau suatu kasus/beragam kasus melalui pengumpulan data yang mendalam serta melibatkan berbagai sumber informasi yang kaya dalam suatu konteks. Sistem ini terikat oleh waktu dan tempat, sedangkan kasus dapat dikaji dari suatu program, peristiwa, aktivitas atau suatu individu (Creswell, John W: 1996).

Dengan perkataan lain, studi kasus merupakan penelitian dimana peneliti menggali fenomena tertentu (kasus) dalam suatu waktu kegiatan (program, even, proses, institusi atau kelompok sosial) serta mengumpulkan informasi secara terinci dan mendalam dengan menggunakan berbagai prosedur pengumpulan data selama periode tertentu.

Teknik pengumpulan data penelitian ini menggunakan studi literatur atau dokumen, baik dari jurnal, makalah, buku maupun sumber informasi lainnya yang membahas mengenai implementasi nilai-nilai sibaliparri. Literatur atau dokumen adalah peristiwa yang sudah berlalu. Dokumen atau literatur bisa berbentuk 
tulisan, gambar atau karya-karya monumental dari seseorang (Sugiyono, 2012).

\section{HASIL DAN PEMBAHASAN}

\section{Landasan dan Konsepsi Sibaliparri}

Sibaliparri telah menjadi bagian dari identitas diri orang-orang Mandar. Ia tak hanya menjadi penanda kehidupan rumah tangga, tapi juga menjadi penanda eksistensi nilai-nilai luhur kebudayaan yang sekaligus menjadi penopang kehidupan sosial dalam berbagai aspek.

Meski demikian, sangat disayangkan, karena sejauh ini, sibaliparri masih dipahami sebatas relasi kerjasama atau tanggung jawab suami-isteri, khususnya dalam hal ekonomi rumah tangga, belum sampai pada taraf implementasi nilai-nilai sibalipaari dalam ruang lingkup kehidupan sosial.

Meski tradisi sibalipaarri sudah ada jauh sebelum datangnya Islam, namun subtansi dan inplementasinya sarat dengan nilai-nilai Islam. Kata sibaliparri berasal dari suku kata si yang artinya saling, bali yang berarti lawan. Namun jika diawali dengan me menjadi mebali bermakna menjawab atau membantu. Sementara parri berarti susah. Sibaliparri berarti saling membantu dalam segala sesuatu baik secara materi maupun spiritual. Lebih jauh, dalam kamus bahasa Mandar, sibaliparri digambarkan dalam ungkapan "muaq meloqo maqita tobaine, itai tabaine iya mala disiolang sibaliparri" (jika hendak beristri, maka carilah perempuan yang bisa diajak bekerjasama atau saling membantu) (Bodi, 2010:90).

Sibaliparri dalam konteks kehidupan rumah tangga ini menekankan pola relasi proporsional dan tidak membedakan status dan jenis kelamin. Nilai utama yang mendasari sibaliparri ini adalah kesetaraan, keadilan dan kemaslahatan untuk kebaikan bersama.

Nilai yang sekaligus menjadi salah satu tujuan perkawinan dalam Islam, sebagaimana yang digambarkan Allah dalam Alquran: "Dan diantara tanda-tanda kebesaran-Nya, dialah yang telah menciptakan pasangan-pasangan untukmu dari jenismu sendiri agar kamu cenderung dan merasa tentram kepadanya, dan Dia yang telah menjadikan di antara kamu rasa kasih dan sayang. Sesungguhnya yang demikian itu, benar-benar terdapat tanda-tanda kebesaran Allah SWT bagi mereka yang berpikir (Qs. Al Rum, 30:21).

Sakinah dalam ayat tersebut di atas berasal dari kata sakanah yang berarti tempat tinggal yang menentramkan, sementara mawaddah, menurut pakar tafsir berarti mahabba (cinta), nashihah (nasehat) dan al-shilah (hubungan yang kuat) dan rahmah bermakna kasih, kelembutan, kebaikan dan ketulusan hidup yang harus senantiasa tercurah dalam lingkup kehidupan rumah tangga (Muhammad, 2006:260).

Singkatnya, ayat ini menegaskan bahwa, salah satu tujuan perkawinan adalah terciptanya hubungan suami-istri yang saling mengasihi, menasihati dan hormat-menghormati agar rumah tangga senantiasa menjadi tempat yang menentramkan.

Berdasarkan argumentasi di atas, dapat disimpulkan bahwasanya sibaliparri yang juga merupakan kearifan lokal masyarakat Mandar ini sarat dengan nilai-nilai agama (Islam). Ia adalah pengejewantahan dari nilai-nilai teologis sekaligus menjadi penyempurna nilai-nilai kemanusiaan. Subtansi dari nilai-nilai sibaliparri tiada lain adalah pengejewantahan nilai-nilai tao dan tau.

Nilai-nilai tao yang dimaksud adalah nilai yang terdapat kesadaran beragama dan perilaku beragama orang-orang Mandar yang secara sederhana dimaknai sebagai bentuk keyakinan kukuh kepada Allah SWT. Sementara nilai-nilai tau dimaksudkan sebagai etika kemanusiaan yang dilandasi oleh rasa persaudaraan, kasih sayang, kepedulian, keihlasan, dan kepedulian terhadap sesama (Bodi, 2016: 292).

Atas dasar itu, implementasi dari nilai-nilai sibaliparri tidak hanya sebatas dalam ruang lingkup keluarga, tapi mencakup segala aspek kehidupan sosial dengan bertumpu tradisi dan adat kebiasaan yang berlaku di Mandar. Sibaliparri bisa bermakna sebagai ekspresi nilai-nilai keagamaan dalam konteks kebudayaan, atau pembudayaan nilai-nilai agama dalam kehidupan sosial masyarakat Mandar.

Asumsi ini berangkat dari pandangan yang mengatakan "kita membutuhkan budaya untuk membumikan nilai-nilai agama". Pandangan ini tentu saja bukanlah sesuatu yang baru bagi orang-orang Mandar, sebab jauh sebelumnya, sudah ada pasang (pesan) kearifan leluhur mereka tentang relasi agama dan budaya, sebagaimana bunyi pasang di bawa ini. "Naiya adaq, saraq nala sulo, naiyya saraq adaq nala gassing, matei adaq muaq andiang saraq, matei toi saraq muaq andiang adaq. (Adapun agama, adat adalah kekuatan, sementara adat, agama adalah sulu; mati adat kalau tidak ada agama, mati agama kalau tidak ada adat) (Bodi: 2008:72).

Adaq adalah hukum yang berlaku di masa kerajaan yang kemudian berlanjut menjadi tradisi hingga datangnya agama Islam di 
Mandar. Adaq merupakan sumber nilai tertinggi disamping nilai agama yang menjadi rujukan orang-orang Mandar. Adaq berperan penting dalam membentuk karakter manusia malaqbi (bermartabat). Nilai-nilai amalaqbian itu terlihat pada keikhlasan, kejujuran, kebenaran, keadilan, keberanian, kepatuhan, kedamaian dan kesabaran (Ismail, 2012:60).

Olehnya itu, agama dan kebudayaan di Mandar adalah dua hal yang tak terpisahkan, lewat kebudayaan nilai-nilai Islam itu ditanamkan. Beragama dengan mengebiri kebudayaan tidak hanya menampilkan corak keberagamaan yang kaku dan kering, tapi juga menjadi sesuatu mustahil dalam upaya pembentukan karakter manusia-manusia Mandar yang berbudaya. Meminjam istilah Nazar Hamid Abu Zaid, untuk membangun peradaban yang berkemajuan, manusia harus mampu mengawinkan tradisi langit (wahyu) dan tradisi bumi (kebudayaan) (Zaid dalam Prawono, 2007). Tawaran Nasar Hamid Abu Zaid ini sejalan dengan pandangan Abdurrahman Wahid yang menginginkan pembumian nilai-nilai keagamaan (Islam) dalam konteks kehidupan sosial manusia (Wahid, 2001:117-136).

\section{Implementasi Nilai-nilai Sibaliparri}

Esensi terdalam dari konsepsi sibaliparri ini tidak hanya terlihat pada nilai-nilainya yang abstrak, melainkan pada keteladanan. Jika umumnya, konsepsi sibaliparri dipahami sebagai kerjasama atau tolong-menolong, maka tentu saja ia tak hanya menjadi bagian dari pengejewantahan nilai-nilai kebudayaan, tapi juga, tapi juga bentuk pengamalan nilai-nilai Alquran; "Dan tolong menolonglah kamu dalam mengerjakan kebajikan dan takwa, dan jangan tolong menolong dalam perbuatan dosa dan pelanggaran. Dan bertaqwalah kepada Allah SWT, sesungguhnya Allah SWT amat berat siksaan-Nya." (Qs. Al-Maidah, 5:2).

Kerja keras adalah wujud nyata dari nilainilai sibaliparri. Ia tak tak hanya terkait dengan urusan material, tetapi juga hal-hal yang sifatnya immaterial, dan tentu saja pendidikan menjadi salah satu bagian darinya. Jika pendidikan dimaknai sebagai proses pemanusiaan manusia, yang puncaknya bisa ditemukan pada diri atau masyarakat yang pendidikan dan berbudaya (Tilaar, 2001; 189 dan Shochib, 1998:134), maka sudah barang tentu pendidikan dalam rumah tangga menjadi sesuatu yang sangat prinsipil, karena dari sinilah pendidikan dan pembentukan karakter manusia pertama kali dilakukan.
Demikian pula, jika keluarga diibaratkan sebagai lembaga pendidikan, maka orang tualah (suami-isteri) yang menjadi guru, sementara anak-anak menjadi muridnya. Oleh karenanya, jika sakinah adalah salah satu tujuan perkawinan dalam Islam, maka sudah barang tentu pula pendidikan rumah tangga adalah salah satu bagian terpenting di dalamnya, karena dari sinilah anak-anak pertama kali belajar tentang kehidupan, dan sekaligus mengenal peradaban pertama dalam kehidupannya. Meski hal ini tidak mudah, karena pendidikan dalam lingkup rumah tangga membutuhkan waktu yang panjang, namun harus disadari bahwasanya pendidikan rumah tangga punya efek sosial yang luar biasa. Ibarat sungai, rumah tangga adalah hulu, jika ia tercemari maka niscaya akan mencemari sungai seluruhnya (Amin, 2012:113-114).

Makanya itu, tidak mengherankan jika kata birwalidain (berbuat baik kepada kedua orang tua) menjadi penekanan dalam Alquran, karena anak-anak lebih dekat dengan orang tua, di mana orang tua diharapkan bisa menjadi teladan baginya. Pada konteks itulah, implementasi nilai-nilai sibaliparri menjadi sangat penting. Ia tidak hanya hadir dalam bentuk kerjasama secara lahir, tapi juga didasari oleh kesadaran dan kepedulian tentang masa depan anak dan lingkungan sosialnya. Singkatnya, pendidikan rumah tangga adalah pondasi kehidupan berbangsa dan masyarakat. Rusaknya tatanan kehidupan rumah tangga adalah awal dari mala petaka keduanya.

Dalam konteks kehidupan rumah tangga di Mandar, pendidikan yang pertamakali dicanangkan adalah akhlak dan moralitas, khususnya pada anak-anak usia dini. Para orangtua mendidik anak-anak mereka agar memiliki budi pekerti yang mulia. Pendidikan budi pekerti yang dimaksud adalah bertutur kata yang baik (loa macoa) serta bersikap dan bertindak yang mulia (kedo mala'bi). Kedua norma ini adalah hal yang sangat prinsipil di Mandar, sebab kedua norma tersebut sekaligus menjadi penanda kemanusiaan seseorang.

Sebagaimana ungkapan yang mengatakan loa anna kedodi tu'tia mappannassa atauang (karena tutur kata dan perilaku mulah sehingga engkau disebut sebagai manusia) (Bodi: 2016:316). Saking pentingnya pendidikan budi perkerti ini, juga tergambar dalam sebuah pasang berbunyi "Palakalaqbi to tondodaiqmu, pakarayai sippatummu, asayanggi to tondonaumu”. Artinya; hormatilah yang lebih tua, hargai sebayamu, dan sayangi orang-orang di bawahmu. (Bodi, 2008:.184). 
Pasang tersebut di atas menyampaikan pentingnya relasi kemanusiaan dibangun dia penghargaan terhadap sesama. Pasang ini sangat popular di Mandar, karena selain didendangkan dalam sebuah lagu, juga dalam rumah tangga, pasang ini kerap dijadikan sebagai bahan pembelajaran kepada anak-anak usia dini. Hal ini sekaligus membuktikan bahwasanya pendidikan karakter sudah lama terbangun di Mandar, bahkan ia menjadi bagian dari harga diri.

Hal itu terlihat pada diri seseorang yang merasa malu (masiri') jika mendengar atau menemukan anaknya bersikap kurang ajar (pasayu) terhadap orang lain. Karena perilaku demikian, tak hanya menginjak-injak harga diri seseorang, tapi juga diri sendiri dan keluarga. Makanya itu, pasayu di Mandar dianggap sebagai aib, selain menjadi buah bibir masyarakat, juga merupakan wujud dari kegagalan pendidikan moral dalam rumah tangga.

Pentingnya pendidikan budi pekerti, khususnya dalam lingkup rumah tangga ini, berangkat dari asumsi bahwasanya sikap dan perilaku anak merupakan cerminan kehidupan rumah tangga. Pada konteks inilah sibaliparri menjadi sebuah keharusan dalam upaya mewujudkan karakter manusia Mandar yang bersusila tinggi (lihat Rahman, 12014: 146149).

Dari uraian di atas tampak bahwasanya kepedulian orang tua dalam kehidupan rumah tangga guna menanamkan budi pekerti yang mulia sangat sejalan dengan tujuan pendidikan Islam. Apalagi pendidikan Islam sangat menekankan atau menitikberatkan pada pembinaan akhlak (moral) anak sejak dini. Upaya yang dilakukan orang tua (suami-istri) ini sekaligus membantu pihak lembaga pendidikan formal (sekolah) dalam upaya membentuk pribadi manusia yang berkualitas. Yakni pribadi mampu menyeimbangkan aspek kognitif, afektif dan psikomotor dalam diri anak. Meski demikian, hal yang sangat mendasar dari wujud siballiparri ini adalah penanaman akhlak sejak dini, karena aspek ini sangat menentukan perkembangan siswa (anak) selanjutnya.

\section{Sibaliparri dan Tantangan Masa Depan \\ "La taksiru auladakum ala adabikum, faiinahum makhlukuna lizamanin gaira lizamanikum." (Janganlah engkau memaksakan anak-anakmu sesuai dengan pendidikanmu, karena sesungguhnya mereka diciptakan untuk zaman yang bukan zaman kalian).}

Demikian pesan Imam Ali dalam kitab alImam Ali, Almukhtar Min Bayani Wa Hikamihi yang disusun oleh Syaikh Fadhlullah al-Ha'iri. Pesan ini menyampaikan pentingnya orangtua memperhatikan pendidikan anak, sebab ia tidak hanya menjadi anak biologis kita, tapi juga kelak akan menjadi anak zaman di masa mendatang. Makanya itu, lewat pesan tersebut, Imam Ali menekankan pentingnya pendidikan agar tidak gagap dalam menghadapi perkembangan zamannya.

Meski secara historis, pesan Imam Ali ini sudah berlalu, seiring dengan kepergian penuturnya, namun secara nilai pesan bijak ini masih sangat relevan dijadikan sebagai nasihat, apalagi di tegah perkembangan zaman yang makin menggila, ditandai dengan gaya hidup mewah, boros dan hedonis dan tidak jarang membuat sifat dan perilaku manusia menjadi buas, liar dan egois. Budaya malu (siri') dan nilai-nilai agama yang sejatinya menjadi benteng perisai harga diri seolah tidak mampu membendung ambisi manusia tersebut. Akibatnya, tampak kehidupan sebagian manusia tak ubahnya seperti binatang (Ngeljaratan: 2019:33).

Fenomena lain di tegah perkembangan zaman adalah munculnya pergeseran nilai, ideologi, dan cara pandang. Meski hal ini dilihat sebagai sesuatu lumrah terjadi, namun sangat memiriskan karena tidak jarang hal itu berdampak pada sendi-sendi kehidupan sosial. Ikatan kebersamaan yang dulunya menjadi kebanggaan, perlahan mengalami pergeseran ke pola hidup individualis. Apalagi dengan kehadiran teknologi yang turut serta mendominasi segala lini kehidupan manusia. Tanpa disadari produk zaman modern tersebut, perlahan mengubah cara pandang kita tentang hakikat realitas.

Pengaruh teknologi seperti gadget tidak hanya membuat hidup manusia mudah dan instan, tapi juga telah berhasil merebut ruang privasi dan perhatian manusia. Melalui fitur media sosialnya, gadget telah berhasil membentuk karakter manusia individualis. Ia lebih diutamakan atau fokus perhatian ketimbang anak, istri, keluarga, dan kerabat sosial lainnya. Sehingga tanpa disadari, kita telah terjebak dalam fase krisis perjumpaan (silaturahmi).

Dampak lain dari perkembangan media sosial adalah berubahnya cara pandang generasi muda kita, bahkan tidak jarang sebagian dari mereka terlibat sebagai pelaku teror mengatasnamakan agama. Penelitian WAHID Foundation yang diluncurkan pada 1-3 Agustus 2016 lalu cukup mencengangkan. Penelitian 
tersebut menyebutkan bahwa anak-anak muda lebih berpotensi melakukan tindakan anti perdamaian dan radikalisme dibanding mereka yang sudah berusia tua. Menurut Arief Rahman (dalam Maarif, 2017:151) radikalisme terjadi di kalangan anak muda (siswa) tersebut akibat hilangnya keteladanan di sekolah, rumah dan masyarakat sekitar. Mereka telah tercerabut dari akar-akar nilai agama, etika, moral dan kemanusiaan.

Rutinitas orangtua yang seolah tak mengenal waktu ini, di satu sisi membuat mereka tidak sadar akan tanggungjawab moral anak-anaknya. Kurangnya perhatian serta ruang kebersamaan dalam kehidupan rumah tangga menjadi salah satu penyebab anak-anaknya mencari perhatian di luar lingkungan rumah tangga atau sibuk dengan benda mati bernama smartphone.

Jika dulunya, anak-anak tertidur diiring pesan-pesan moral melalui cerita-cerita dongeng, namun saat ini, hal dianggap sudah tidak zaman lagi, sebab gadget jauh lebih menarik ketimbang cerita-cerita moral tersebut. Akibatnya, pusat pendidikan moral anak-anak adalah teknologi. Bahkan tak jarang ditemukan anak-anak lebih memperhatikan smartphone$n y a$, daripada buku pelajarannya.

Tak hanya itu, jarak orangtua dengan anak tidak hanya terjadi dalam hal fisik, tapi juga batiniah. Padahal anak butuh sentuhan kasih sayang dan persahabatan, karena dengannya ia akan belajar menemukan arti cinta dalam kehidupannya. Makanya itu, cerita atau nasihat moral menjelang tidur itu, sangatlah penting karena ia bisa merekatkan menjaga hubungan baik antara anak dan orangtua, serta berharap kelak anaknya hidup menjadi orang yang bermoral dan beretika.

Olehnya itu, seiring dengan perkembangan zaman, spirit dan nilai-nilai sibaliparri semakin tertantang dan tidak menutup kemungkinan, di masa mendatang warisan leluhur Mandar ini akan sirna ditelan zaman. Pada konteks inilah penting untuk menjaga tradisi dan warisan leluhur Mandar tersebut melalui keteladanan. Sebab menjaga tradisi dengan mengedepankan keteladanan jauh lebih penting dari pada seruan keteladanan. Kerjasama, persaudaraan, kasih sayang, keihlasan, dan kepedulian terhadap sesama yang notabene menjadi inti dari nilainilai sibaliparri hanya mungkin bisa hidup langgeng jika nilai-nilai tersebut terus diteladankan, khususnya dalam lingkup keluarga.

\section{KESIMPULAN}

Sibaliparri adalah nilai-nilai kebudayaan yang sudah lama mengakar dalam tatanan kehidupan sosial masyarakat Mandar. Sibaliparri berasal dari suku kata si yang artinya saling, bali yang berarti lawan, namun jika diawali dengan me menjadi mebali bermakna menjawab atau membantu, sementara parri berarti susah. Sibaliparri berarti saling membantu dalam segala sesuatu baik secara materi maupun spiritual.

Meski sibalipaari, umumnya dipahami sebagai filosifi kehidupan berumah tangga, namun dampak sosial yang cukup luar biasa, karena implementasinya nilai-nilai dilakukan melalui pendidikan dengan mengutamakan keteladanan hidup yang menitikberatkan pada pembinaan akhlak (moral) anak sejak dini. Upaya yang dilakukan orangtua (suami-istri) berdampak positif terhadap lembaga pendidikan formal (sekolah) dalam upaya membentuk pribadi manusia yang berkualitas, yakni pribadi mampu menyeimbangkan aspek kognitif, afektif dan psikomotor dalam diri anak.

Demikian pula, jika dalam Islam, setiap keluarga dianjurkan untuk mendidik anakanaknya, maka melalui sibaliparri, orang-orang Mandar mengimplementasikan anjuran agama tersebut. Sehingga nilai-nilai sibaliparri sejalan dengan nilai-nilai agama (Islam) karena ia merupakan pengejewantahan nilai-nilai teologis sekaligus menjadi penyempurna nilai-nilai kemanusiaan. Nilai-nilai kemanusiaan itu, terlihat pada etika sosial yang dilandasi oleh rasa persaudaraan, kasih sayang, keihlasan, dan kepedulian terhadap sesama.

\section{DAFTAR PUSTAKA}

al-Ha'iri, Syaikh Fadhlullah, Tanya Aku Sebelum Kau Kehilangan Aku, Kata-kata Mutiara Ali Bin Abi Thalib, diterjemahkan dari kitab al-Imam Ali, Almukhtar Min Bayani Wa Hikamihi oleh Tholib Anis. Cet X, 2012. Bandung; Pustaka Hidayah.

Amin, Ahmad, 2012. Kitab Akhlak, Wasiat Terakhir Gus Dur. Terjemahan Hasan Aminuddin. Surabaya: Quntum Media.

Bodi, Muh. Idam Khalid, 2007. Lokal Wisdom, Benang Untaian Mutiara Hikmah Dari Mandar Sulawesi Barat. Cet. II; Jakarta: Nuqtah.

2010. Kamus Besar Bahasa Mandar-

Indonesia. Cet. I; Solo: Zadahadiva Publishing. 
2016. Sibaliparri: Gender Masyarakat Mandar. Solo: Zadahadiva Publishing. .2019. Konflik Identitas, Kajian Terhadap Pemekaran Sebuah Daerah. Yogyakarta: Lintas Nalar.

Creswell, John. W. 1998. Qualitative Inquiry and Research Design: Choosing Among Five Traditions, London: SAGE Publication.

Imail, Arfuddin, 2012. Agama Nelayan, Pergumulan Islam dengan Budaya Mandar. Yogyakarta: Pustaka Pelajar.

Ma'ud, Rahman, Darmawan, 2014. Puang dan Daeng, Sistem Nilai Budaya Orang Balanipa Mandar. Solo: Zadahadiva Publishing.

Maarif, H. Nurul, 2017. Islam Mengasihi, Bukan Membenci. Bandung: PT Mizan.
Muhammad, Husain, 2006. Spritualitas Kemanusiaan, Presfektif Islam Pesantren. Yogyakarta; Pustaka Rihlah.

Ngeljaratan, Ishak, 2019. Quo Vadis Indonesia. Global Publishing.

Prawono, Suaib Amin, 2007. Budaya Mandar dalam Kultur Global. Makalah Diskusi Pelatihan Advokasi Budaya DPP IPMIM Majene di Makassar.

Sugiyono. 2012. Metode Penelitian Kuantitatif, Kualitatif dan Kombinasi (Mixed Methods). Alfabeta, Bandung.

Wahid, Abdurrahman, 2001. Pergulatan Negara, Agama dan Kebudayaan. Cet:II. Depok: Desantara. 